\title{
TEORÍA Y PRÁCTICA DE LA MEDICINA VISIGODA. DEL ENCICLOPEDISMO DE ISIDORO A LA ENFERMERÍA MONÁSTICA
}

\author{
Pablo C. Díaz \\ Universidad de Salamanca \\ Email: pcdiaz@usal.es \\ ORCID iD:http://orcid.org/0000-0001-6706-2781
}

Recibido: 10 octubre 2018; Aceptado: 22 julio 2019

Cómo citar este artículo/Citation: Díaz, Pablo C. (2020), "Teoría y práctica de la medicina visigoda. Del enciclopedismo de Isidoro a la enfermería monástica", Asclepio, 72(1): p299. https://doi.org/10.3989/asclepio.2020.08.

RESUMEN: Cuando leemos la obra enciclopédica de Isidoro de Sevilla da la sensación de que la medicina clásica había llegado al mundo visigodo plena de racionalidad, como un conocimiento erudito y bien asentado. Sin embargo, cuando se buscan las evidencias de la práctica médica esta resulta más difícil de atestiguar. El médico se presenta como una figura excepcional y sus cuidados dirigidos a una minoría privilegiada. Cuando Isidoro enfrenta la enfermedad en su obra monástica parece claro que la salud del monje es objeto de su preocupación, pero enseguida apreciamos que su propio concepto de la enfermedad y sus causas ha tomado otros derroteros. La enfermedad ya no es solo una alteración del equilibrio del cuerpo, la enfermedad puede convertirse en una prueba de la desaprobación de Dios. Dentro de las opciones curativas propuestas por Isidoro en sus Etimologías: la dieta, el uso de medicamentos y la cirugía, solo la primera parece aplicarse en el contexto monástico. Esta opción, que es común al resto de la literatura ascética y de las reglas del entorno, deviene tanto en un vehículo de prevención de enfermedades, como en un objeto de disciplina moral y de control de la voluntad de los monjes.

PALABRAS CLAVE: Medicina; enfermedad; dieta; monje; monacato.

\section{THEORY AND PRACTICE OF VISIGOTHIC MEDICINE. FROM ISIDORE'S ENCYCLOPEDISM TO MONASTIC NURSING}

\begin{abstract}
When we read the encyclopaedic work of Isidore of Seville, we may get the feeling that classical medicine had reached the Visigoth world in a state of full rationality, as an erudite and well established knowledge. However, evidence of medical practice is more difficult to be found. The doctor is shown as an exceptional figure, and medical care is available only for a privileged minority. When Isidore faces the disease in his monastic work it seems clear that the monks' health is an object of his concern, but we immediately notice that his own idea of disease and its causes has taken a different course. The disease is no longer only an alteration of the balance of the body, the disease may become a proof of God's disfavour. Among the healing options proposed by Isidore in his Etymologies, we can found diet, medicines and surgery, but only the first one seems to apply in the monastic context. This option, which is common to the rest of the ascetic literature and the rules of the surrounding areas, becomes a vehicle of disease prevention as well as an object of moral discipline and control of the will of the monks.
\end{abstract}

KEY WORDS: Medicine; disease; diet; monk; monasticism.

Copyright: @ 2020 CSIC. Este es un artículo de acceso abierto distribuido bajo los términos de la licencia de uso y distribución Creative Commons Reconocimiento 4.0 Internacional (CC BY 4.0). 


\section{ISIDORO Y LA MEDICINA CLÁSICA}

El estado saludable del cuerpo es una imagen que nosotros identificamos fácilmente con la ausencia de la enfermedad. Un cuerpo sano es aquel que no necesita de medicina alguna para hacer frente a sus actividades cotidianas, que no sufre un dolor crónico o incapacitante, que no está atrapado por la debilidad, permanente o circunstancial, que goza de fuerza acorde con su naturaleza y constitución. La medicina es el medio por el cual un cuerpo que ha perdido ese equilibrio busca restablecerlo, mientras el médico es el experto que dispone de los conocimientos para procurarlo. Esas son las ideas esenciales que Isidoro recoge en el inicio de su obra De Medicina, inserta como libro cuarto en sus Etimologías:

Medicina es la ciencia que protege o restaura la salud del cuerpo, y su campo de acción lo encuentra en las enfermedades y las heridas. A ella le incumben no solo los remedios que procura el arte de quienes con toda propiedad se llaman médicos, sino, además, la comida, la bebida, el vestido y el abrigo; todo aquello, en fin, que sirve a la defensa y protección, gracias a lo cual nuestro cuerpo encuentra salvaguardia frente a los ataques $y$ peligros externos (Etym. 4.1)1.

Este libro, complementado con las páginas que le dedica a la anatomía del cuerpo humano y a sus edades (Etym. 11.1-2), o las que, en otro contexto, consagra a las hierbas medicinales (Etym. 17.7-9), constituye un compendio enciclopédico que apenas nos informa de la práctica médica contemporánea. La mayoría de los autores considera que Isidoro, en las Etimologías, se enfrenta a la medicina como un gramático, un celoso guardián del lenguaje (Fontaine, 1988; Díaz y Díaz, 2009, pp. 163-214; Kaster, 1988; Ferraces Rodríguez, 2005b), que no está especialmente interesado por la medicina y que sus destinatarios no son los profesionales médicos o los estudiantes de medicina, sino una élite culta a la que, además de otras materias, también interesa la medicina (Sharpe, 1964, p. 11). Eso no impide que su texto nos dé cuenta de cuál pudiese ser el conocimiento médico en la península ibérica del siglo VII, esencialmente de las ideas comunes y generalmente aceptadas. Isidoro es un buen conocedor de Hipócrates (Kibre, 1945, p. 372), está familiarizado con Dioscorides y Galeno, mientras que no parece conocer con detalle la obra médica de Celso. Con todo, su información parece derivar más directamente de Caelius Aurelianus, Casius Felix y el pseudo-Soranus (Fontaine, 1959, pp. 666-667; Fischer, 2000), autores africanos del siglo V, especialmente del primero, quien habría transmitido la obra del médico griego Sorano de Éfeso y cuyo método expositivo -etiología, diagnóstico y terapia de cada enfermedad- (Van der Eijk, 2005, pp. 299-327), así como su lenguaje, parecen reflejarse en el texto de Isidoro (Sharpe, 1964, pp. 12-14; Ferraces Rodríguez, 2005a; Vázquez Buján, 2005).

Atendiendo a lo dicho, parecería claro que no hay originalidad alguna en Isidoro. Para él «todas las enfermedades tienen su origen en los cuatro humores» (Etym. 4.3), principio hipocrático derivado de los cuatro elementos esenciales de Empédocles (Etym. 11.1.16), que, sustentado por el peso de las enseñanzas de Galeno y de sus seguidores, iba a dominar la práctica médica hasta la llegada de la medicina moderna (Vázquez Buján, 1991; Grmek, 1998; GarcíaBallester, 2001, pp. 129-144; Nutton, 2008). Isidoro conoce las tres escuelas médicas definidas en la Antigüedad, la metódica, que atribuye a Apolo, acompañada de medicamentos y conjuros; la empírica, o experimental, patrocinada, dice, por Esculapio y que no atendía tanto a los síntomas como a la experiencia, y, por último, la lógica, o racional, que atribuye a Hipócrates (Etym. 4.4.1). En su percepción, que era la que había alcanzado mayor aprecio entre los contemporáneos, considera que esta última es la correcta, pues «investigaba, poniendo en juego la razón, cuál era la causa de las enfermedades» (Etym. 4.4.2), sin dejar de considerar que la experiencia del médico era igualmente importante, en lo que asumía una práctica ecléctica.

Por otro lado, Isidoro recoge los tres métodos curativos que siguen estando en la base de la práctica médica: el dietético, el farmacéutico y el quirúrgico. Según él:

La dieta es la observación de un sistema de vida. La farmacia es la curación mediante medicamentos. La cirugía, la intervención por medio de un instrumental; pues cuando no se experimenta reacción ante el remedio de los fármacos, es preciso operar con el bisturí (Etym. 4.9.3).

A la hora de esa práctica, Isidoro recurre de nuevo a Galeno. La dieta, la comida y la bebida, formaban parte de las sex res non naturales enunciadas por el médico clásico como elementos esenciales de la salud del cuerpo (Rather, 1968; García-Ballester, 2013). Evidente es, igualmente, la referencia galénica al plantear que «toda curación comporta el empleo de elementos contrarios o semejantes» (Etym. 4.9.5; Hankinson, 2008). Aunque es poco probable que 
Isidoro haya llegado a Galeno de manera directa, sino recurriendo a las mencionadas simplificaciones de su obra que se habían extendido por todo el Occidente y que habían incorporado los escritores eclesiásticos cuando la Iglesia asumió que cuidar de los enfermos era uno de los mandatos de Cristo a los creyentes. Sin olvidar que el cuerpo humano debía cuidarse porque era portador del alma y por tanto templo de Dios (Sigerist, 1943, pp. 69-70; Amundsen, 1982; Flemming, 2010, pp. 23-31; Heyne, 2011). Aunque estos autores siempre mantendrán un equilibrio entre la eficacia de la medicina y la creencia en la omnipotencia de Dios, ya que, en última instancia, todo beneficio para el hombre procede de su voluntad. De acuerdo a estos principios, Isidoro insiste en que los remedios medicinales no deben rechazarse, y recurre a referencias escriturarias para hacer convincente su argumento (Etym. 4.9.1). Se trataba de racionalizar la enfermedad; si esta se reducía a un castigo divino la práctica médica dejaba de tener sentido.

En cualquier caso, Isidoro parece rendirse ante la irreductibilidad de la peste, considerando que ha sido permitida por Dios, aunque sin negar su fundamento físico en el aire corrompido (Etym. 4.6.17). En apariencia, esta es la única etiología contemplada, lo que implica la idea de 'contaminación' y por tanto un alto sentido de racionalidad (Rosenberg, 1992, pp. 293302). De igual modo, ya en el siglo III, Cipriano de Cartago (De mortalitate) había interpretado la peste como una prueba divina, puesto que ante el temor de la muerte se hacía evidente la rectitud de cada hombre (Piazza, 2007). Es probable que brotes recientes de peste en la península ibérica hubiesen proporcionado a Isidoro una percepción especial y próxima de dicha enfermedad (Kulikowski, 2007). Como en el caso de los episodios de la plaga en el Imperio oriental a partir de los años 541-544, la explicación metafísica se impondría sobre una lectura racional de causalidad biológica (Noy, 2006, pp. 34-36; Stathakopoulos, 2006), más allá de la descripción de sus síntomas que transmiten Procopio y otros escritores contemporáneos (Stathakopoulos, 2004, pp. 134-143). Con todo, aunque, especialmente en los relatos hagiográficos, el mal corporal puede llegar como una prueba o como un castigo de Dios, respuesta de la voluntad divina ante los pecados de los hombres (Laín Entralgo, 1961, pp. 78-84), el cristianismo antiguo asumió, hasta donde fue capaz, los criterios médicos clásicos y buscó una explicación física a la mayoría de las enfermedades (Temkin, 1991, pp. 126-147; Ferngren, 2009, pp. 13-41; Mayer, 2015).
Ahora bien, el estudio intrínseco de las nociones médicas contenidas en las Etimologías (García Pérez, 2001; López Piñero y Ferrandiz Araujo, 2008), la incesante búsqueda de sus fuentes informantes (Ferraces Rodríguez, 1994; Fischer, 2005; Maire, 2005), el apasionante rastreo desde el punto de vista léxico (Montero Cartelle, 2003; Ferraces Rodríguez, 2005a), la apabullante tarea cuando se trata de desentrañar la historia de su tradición manuscrita (Codoñer Merino, 2005a; 2005b), o el alcance de la influencia posterior del texto (Fidora, 2000; Martínez Gázquez, 2005; Cardelle de Hartmann, 2014) apenas nos ayudan a conocer cuál era el nivel de la práctica médica en el momento en que Isidoro estaba redactando el texto en torno al año 620.

No conocemos con detalle el sistema de aprendizaje, aparentemente basado de manera exclusiva en la relación maestro/discípulo, y sustentado esencialmente en la experiencia, con el apoyo de recetarios anónimos. Esta enseñanza aparece regulada en la legislación visigoda, donde se establece que por la instrucción de su aprendiz (discipulus/famulum) el maestro recibía la cantidad de doce solidi (LV 11.1.7; Menéndez Bueyes, 2013, pp. 26-32). En términos absolutos no parece una cantidad muy elevada si, por ejemplo, la comparamos con las compensaciones económicas en caso de lesiones entre libres: doce solidi era la indemnización por la pérdida de un diente en una reyerta o como consecuencia de una agresión ( $L V$ 6.4.3). Sin embargo, la misma legislación considera que un solidus es cantidad suficiente para mantener durante todo un año a un niño (LV 4.4.3). En la segunda mitad del siglo VI, Vicente, obispo de Huesca, establece en su testamento la entrega de un puer de nombre Dalmaciano, probablemente un educando de la propia iglesia catedral, al médico (aciatro) Severo para que aprendiese con él el oficio (Fortacín, 1983, pp. 59-64; Díaz, 1998). Dada la imprecisión del texto, no podemos concluir cuál era la condición social del joven, ni si este volvería como médico a la iglesia oscense tras completar su aprendizaje, lo que es probable ya que los obispos tenían muy limitado el derecho a liberar a los dependientes de la diócesis (Roca, 2015); lo único que establecía el testador era el pago de la formación como médico de un muchacho dependiente de la diócesis, en lo que constituiría la forma habitual del aprendizaje médico, basado en la relación maestro/discípulo, como hemos anotado, hasta muy avanzada la Edad Media (García Ballester, 1994).

La posibilidad de que el puer Dalmaciano fuese un dependiente de la diócesis no debe llevarnos a equí- 
voco sobre el lugar que la profesión médica pudiese ocupar en la sociedad visigoda. No parece que la profesión médica esté en manos de siervos, o de judíos (Granjel, 1981, p. 48), sino que participa de un prestigio que se habría incrementado a lo largo del Bajo Imperio romano (Andorlini y Marcone, 2004, pp. 170-176; Rémy y Faure, 2010, pp. 39-54). La legislación visigoda establece que el servicio del médico se hace bajo contrato (ad placitum); tras haber visto la herida, o emitido un diagnóstico sobre los síntomas, y después de formulada una caución (cautione emissa), el médico procedía a prestar sus cuidados, donde las condiciones del tratamiento, establecidas incluso en un documento escrito, equivalen a un contrato ( $L V$ 11.1.3). Esta prestación libre de servicios a cambio de dinero es algo absolutamente excepcional en el panorama legal y social del mundo post-romano, cuando casi todas las relaciones eran producto de un sistema de dependencias (Petit, 1982, p. 17). El contrato implicaría la fijación de la cuantía de la prestación (merces) y la obligación del pago. Como en muchos otros negocios, es posible que existiese una fórmula predeterminada para este tipo de contrato, pero en la colección formular visigoda no se ha conservado, lo que puede ser un hecho casual y no necesariamente consecuencia de su limitado uso.

Isidoro pide a los médicos que tengan en cuenta la condición económica de los enfermos a la hora de fijar sus honorarios y que no se lucren a costa de los pobres: Pauperes attende medice censum atque potentis / Dispar condicio dispari habenda modo est / Si fuerit diues sit iusta occasio lucri / Si pauper merces sufficit mea tibi (Versvs 18; Temkin, 1979). Ahora bien, el pago se efectuaba siempre y cuando el enfermo recuperase la salud, como establece la siguiente ley del código que, además, advierte que en caso de muerte del paciente no se podrá reclamar pago alguno, ni ninguna de las dos partes promoverá acción judicial, por cuanto las condiciones del contrato, que incluye la restitución de la salud, no se habrían cumplido. Es posible que no siempre hubiese un acuerdo satisfactorio; Isidoro advierte al paciente que pague sus honorarios para garantizarse atención si vuelve a caer en la enfermedad: Quos debes medico redde aeger ne mala rursus / Occurrant, currit denuo nemo tibi (Versvs 17). La cuantía del pago parece estar, por tanto, sujeta a un libre acuerdo, sin embargo, el legislador hace una excepción al marcar el precio estipulado para una operación de cataratas (hipocesim), que fija en cinco solidi ( $L V$ 11.1.5). Queremos entender que el legislador pretende limitar los abusos. De nuevo podemos intentar buscar valoraciones relativas, tres solidi era la paga de un año completo si un transmarinus negotiator contrataba un siervo, que además regresaba a su dueño transcurrido ese periodo (LV 11.3.4).

Debemos concluir de esta disposición que la práctica quirúrgica era excepcional, reservada, en todo caso, a una minoría privilegiada. En las fuentes visigodas las referencias a su uso son muy escasas. En el relato hagiográfico de las Vitas Sanctorum Patrum Emeretensium se alude a una intervención ginecológica (la extracción, mediante una punción con el bisturí, de un feto muerto), realizada por un griego, Paulo, en ese momento obispo de la ciudad pero que había ejercido la medicina con anterioridad (VSPE 4.2.1-7). La fuente no desvela si llegó a Mérida con la intención original de ejercer como médico, lo que daría idea de una circulación de profesionales en un ámbito geográficamente amplio. La descripción no es lo bastante detallada como para precisar si se trató de una cesárea como se ha interpretado tradicionalmente (Peset y Vidal, 1962, p. 18), o de una fetotomía por vía vaginal (Curado, 2004, pp. 153-155), pero abunda en la rareza del episodio, que es equiparado prácticamente a un milagro. A pesar de que la familia de la mujer intervenida era excepcionalmente rica, no había encontrado nadie que pudiese atenderla, ninguno de los médicos proporcionados por la misma iglesia emeritense parecía capacitado y el protagonista de la actuación es un extranjero, un griego. La absoluta reticencia que manifiesta a llevar a cabo la operación ha sido puesta ocasionalmente en relación con una hipotética prohibición de que los clérigos practicasen la medicina (Fernández Alonso, 1955, pp. 178-180). Estrictamente no consta que existiese una norma específica que impidiese la práctica médica a los clérigos, aunque estos podían verse afectados por las normas de pureza que les impedían manchar sus manos con sangre humana pues, como dice el propio Paulo, con ellas no podría oficiar ante el altar.

La legislación conciliar alude a la castración y a la circuncisión de los judíos, que exigirían prácticas quirúrgicas, pero en contextos morales y sin valor médico (Zaragoza Rubira, 1968, p. 25). Isidoro en las Etimologías reduce su información sobre la cirugía poco más que a describir algunos de los instrumentos de su práctica: enchiridion, phlebotomum, angistrum, spatomele (Etym. 4.11.1-2); parquedad que contrasta con los hallazgos arqueológicos, incluso los procedentes de la Hispania romana, o con las descripciones de 
las fuentes clásicas (Borobia Melendo, 1988; Jackson, 1990; Bejarano Osorio, 2015). En un símil empleado en la Regula communis, al que volveremos después, se anota que el médico no recurre a la cirugía si puede evitarlo (RCom. 19). Aspecto igualmente derivado de Galeno, que consideraba que el buen médico solo recurría al bisturí cuando la dieta y los fármacos habían fracasado (Grant, 2000, pp. 6-7; Nutton, 2004, p. 240; Vogt, 2008).

Este hipotético prestigio, y la condición privilegiada del médico, no impiden que la práctica esté sometida a numerosas cautelas. La legislación visigoda prohíbe que un médico sangre a una mujer libre si sus parientes no están cerca, solo en caso de extrema necesidad puede hacerlo, pero tienen que estar presentes vecinos o siervos de calidad ( $L V$ 11.1.1). El texto establece que caso de saltarse esta norma, el médico deberá pagar diez solidi a los parientes o al marido, para evitar que diese lugar a algún engaño (ludibrium). El texto no especifica cuál pudiese ser el engaño, aunque parece implícita una preocupación moral. En el caso de la ley siguiente la cautela es mucho más precisa. El médico no podrá atender a prisioneros enfermos si los carceleros no están presentes, para evitar que por medio de aliquid mortiferum ayuden al reo a quitarse la vida, lo que supondría un perjuicio para rationibus publicis (LV 11.1.2). El problema es que los prisioneros mencionados son claramente precisados: comites, tribuni aut vilici, lo que sitúa la ley en un contexto de represión política o legal que excede nuestro interés aquí (Petit, 1982, pp. 14-17); dada la posición social de los interesados debemos suponer que estos médicos eran contratados por ellos mismos, nada hace suponer que actuasen por iniciativa pública.

Antes hemos visto que el médico parecía quedar libre de cualquier reclamación caso de morir el paciente. Tal exención de responsabilidad procedía del derecho clásico que había introducido, sin embargo, una excepción, que la muerte no fuese resultado del proceso de la enfermedad, sino de la impericia del médico. Ahora se establece que si, a consecuencia del mal uso del instrumento para la práctica de una sangría (flebotomum), un paciente se debilita de manera evidente, el médico deberá pagarle 150 solidi, si se trata de un siervo deberá restituirlo con otro de igual valor (LV 11.1.6, antiqua). La redacción fue modificada en tiempo de Ervigio, en la octava década del siglo VII, en un sentido aún más precautorio hacia el médico: si el paciente llegaba a morir como consecuencia de la intervención, de la mala praxis, el médico era entregado a sus parientes para que dispusiesen de él como considerasen oportuno: Si vero mortuus fuerit, propinquis continuo tradendus est, ut, quod de eo facere voluerint, habeant potestatem (LV 11.1.6, Erv.). Esta 'justicia sumaria' no parece muy acorde con las garantías que se asocian con un hombre libre, especialmente privilegiado, como sería el caso del médico. De hecho, la siguiente disposición del código, de nuevo una ley antiqua, establecía que un médico no podía ser encarcelado sin haber sido oído en juicio (inauditum), excepto en caso de homicidio; aunque esa elusión de la cárcel se hace sub fideiussorem, con la garantía de un fiador (LV 11.1.7; Petit, 1983, pp. 137139). Cabe la posibilidad de que según avanzó el reino visigodo la condición del médico se hubiese degradado, o que la muerte como consecuencia de la impericia al practicar la flebotomía se considerase, directamente, una imprudencia punible como homicidio. En cualquier caso, la transferencia de ejecutores de la pena a la propia familia del muerto implica, o bien una indudable degradación de la práctica judicial pública respecto a la tradición del derecho romano, quizás por influencia germánica (Petit, 1982, p. 25), o, alternativamente, un esfuerzo del legislador por adaptar el derecho oficial a la práctica social cotidiana. Buena parte de las modificaciones introducidas por Ervigio en la Lex Visigothorum, y que afectaron casi a la mitad del código, podrían interpretarse en este sentido (Alvarado Planas, 1997, p. 84).

\section{LA PRÁCTICA MÉDICA. EL CUIDADO DEL ENFERMO EN LOS MONASTERIOS VISIGODOS}

A pesar de esta pesimista apreciación sobre las posibilidades que las Etimologías ofrecen a la hora de valorar la práctica médica en época visigoda, el mismo Isidoro se aproximó a la enfermedad en otro de sus textos. La Regula monachorum, redactada muy probablemente entre los años 615 y 627, por lo tanto al tiempo que ordenaba los materiales de las Etimologías (Martín, 2002, pp. 77 y 99), no debe entenderse como un mero ejercicio intelectual; o bien fue elaborada para dotar de una norma homogénea a los monasterios de su diócesis, ya que en el momento de la ordenación, el obispo entrega al abad los símbolos de su poder, entre ellos el librum regularum (Freire Camaniel, 2002; Díaz, 2017, p. 472), o responde al encargo de un abad o de un monasterio particular, como parece sugerir la dedicatoria de algunos 
de los códices de la regla (Mundó Marcet, 1957, p. 106, n. 108). Isidoro declara su intención de construir un texto de disciplina asequible y de fácil comprensión; en la práctica construye la imagen de un edificio idealizado, mezcla de soluciones prácticas y erudición clásica, con unos elementos de cotidianeidad que parecen corresponderse con la realidad física más inmediata (Díaz, 2007). El monasterio de Isidoro contempla un lugar para el tratamiento de los enfermos (locus autem aegrotantium), una enfermería que estará apartada de la iglesia y de las celdas de los monjes, con objeto de que no les perturbe ninguna clase de ruido ni voces (R/sid. 1). Además:

El cuidado de los enfermos ha de ponerse en manos de un monje sano y de vida observante que pueda dedicar toda su solicitud a los mismos y cumpla con la mayor diligencia todo lo que exija la enfermedad [...] A los enfermos ha de servírseles alimentos más delicados hasta que recobren la salud. Pero después que la recobren han de volver a los alimentos de antes. Por el hecho de que a los enfermos se les trate con mayor delicadez, no deben por ello escandalizarse en manera alguna los sanos [...] No es admisible que alguien oculte una enfermedad real o pretexte una supuesta, [...] mas, los que no pueden (trabajar) deben declarar su dolencia [...] Bajo apariencia de enfermedad no ha de usar el monje de baños por el afán de lavar el cuerpo, sino tan solo por necesidad de enfermedad y de polución nocturna (Rlsid. 22).

Isidoro parece reducir el cuidado de los enfermos a su aislamiento en un lugar tranquilo y apacible, atento a la importancia que los tratadistas clásicos dieron a la interactuación entre el espacio y la práctica de la medicina (Rosen, 2012), acompañado de un trato solícito, una dieta especial (delicatoria praebenda sunt alimenta) y una atención específica a la higiene del baño (Borgongino, 2011). Unos cuarenta años antes, en torno al 580, Leandro, hermano de Isidoro y su predecesor en la sede de Sevilla, había escrito una serie de consejos para su hermana Florentina, que había profesado en un monasterio (Velázquez, 1979, p. 22). Aunque el texto se ha transmitido bajo el nombre de Regula, se trata de una exhortación para ensalzar los beneficios y privilegios de la virginidad, para lo cual escribe una serie de amonestaciones y consideraciones. Entre ellas, deja claro que el baño no ha de tomarse «por gusto o por dar hermosura a tu cuerpo, sino tan solo como remedio para la salud. Es decir que usarás el baño cuando la enfermedad lo exija, no cuando el placer lo apetezca» (RLeand. 20). Excepcionalmente, los enfermos y los ancianos pueden utilizar, previa concesión del abad, una celda individual (RIsid. 19). La regla anota que «los que por debilidad corporal (infirmitatem corporis) no pueden trabajar, han de ser tratados con mucha suavidad e indulgencia» (RIsid. 5), probablemente alude en este caso a los de constitución muy débil, o aquejados de una dolencia crónica. Sin embargo, no hay en el desarrollo de las disposiciones ni una sola alusión a la práctica de algún tipo de cura específica, por medio de medicamentos o cirugía. De hecho, el monje enfermero es simplemente un miembro observante de la comunidad, de él se espera que no coma de los alimentos dedicados al enfermo (Rlsid. 2), pero no se alude a que tenga una formación particular. Fructuoso de Braga, que escribe una regla monástica en el entorno de la Gallaecia unas cuatro décadas después, recoge unas consideraciones similares:

Han de escogerse tales enfermeros, que puedan preparar con esmero los alimentos y atenderles con generosa entrega. Con lo que sobra de los enfermos no cometan ningún fraude, ni se manchen ilícitamente comiendo de ello a ocultas (RFruct. 9).

Da la sensación que Isidoro ha reducido la práctica médica en el monasterio al primero de los sistemas de curación, la dieta, que, como había anotado en las Etimologías, era un sistema de vida. Su contenido cotidiano viene especificado en uno de los capítulos:

Durante toda la semana tomarán alimentos pobres de verduras y legumbres secas. Sin embargo, los alimentos serán de muy poca carne con legumbres en los días de fiesta [...] No se ha de prohibir que cualquiera que quisiere pueda abstenerse en la mesa de carnes o vino [...] La refección de la mesa constará de tres platos, a saber, de verduras y legumbres; $y$, de haber, un tercero, de frutas. Asimismo, la sed de los monjes se apagará con tres medidas de vino. Para observar la cuaresma, como suele hacerse, después de cumplido el ayuno, se contentarán todos con solo pan y agua; también se abstendrán de vino y aceite (R/sid. 9).

Sobre las características de la dieta de los enfermos, la única referencia es que es específica, diferenciada de la de los monjes y la de los huéspedes, correspondiendo al despensero hacer la distribución de lo necesario para cada régimen (RIsid. 21). Los enfermos tienen la posibilidad de comer antes de la hora de la refección (Rlsid. 9), estando exentos de las obligaciones del ayuno (RIsid. 3). Exención que se extendía igualmente a los ancianos y a los niños o, en general, a los que están todavía desarrollando su cuerpo (RIsid. 11). La edad, la debilidad y la enfermedad eran causas también para que los jueces eximieran del ayuno a los reos condenados a una dieta de pan y agua ( $L V$ 2.1.19). Es posible que la dieta para los enfermos in- 
cluyese un recurso más frecuente a la carne. En el mencionado texto de Leandro de Sevilla queda claro el carácter terapéutico que se asigna a su consumo:

¿Qué otra cosa podrá hacer un cuerpo alimentado de carne, sino estallar en la concupiscencia y caer en el desenfreno con la lamentable barbarie de la lujuria? [...] Alimentarse de carnes es incentivo de vicios [...] Resérvese el uso de carnes para quienes precisan fuerza corporal [...] Sin embargo, si la enfermedad la obliga a ello, podrá tomarla como medicina (RLeand. 24).

Mismo valor sanador que Leandro da al consumo del vino:

En el uso del vino has de atenerte a la norma del Apóstol cuando dice a Timoteo: Toma un poco de vino por tu mal de estómago y tus frecuentes enfermedades. Cuando dice un poco quiere dar a entender que debe tomarse como medicina, no hasta llegar a la embriaguez [...] Por tanto, la virgen que posee una salud robusta hará bien en abstenerse totalmente del vino; la enferma o delicada, que lo tome como medicina, nunca hasta la ebriedad (RLeand. 19).

La referencia escrituraria procede de San Pablo (ITim 5.23) y es una de las utilizadas posteriormente por Isidoro en las Etimologías (4.9.1) para justificar que no deben rechazarse los remedios medicinales. Al margen las implicaciones del paralelismo de referencias, parece claro que ambos participan de un mismo criterio y que el uso del vino en la dieta de Isidoro tiene también unas motivaciones terapéuticas profundamente arraigadas en la medicina clásica (Jouanna, 2012). Pueden verse, como contraste, los argumentos que el mismo Isidoro da contra el consumo de las bebidas alcohólicas, pues «la embriaguez engendra trastornos mentales, delirio del corazón y el ardor de la lujuria» (Sentent. 2.42.1).

Las indicaciones de Isidoro y de Leandro, más allá de la idiosincrasia particular de cada una de las reglas, son similares a las de los demás legisladores monásticos que conocemos para el periodo. Con mayor o menor profusión en los detalles, la mayoría de las reglas occidentales reflejaron en sus textos la necesidad de atender a los monjes enfermos o débiles y generaron normas de comportamiento o regímenes de alimentación acordes con sus necesidades (Crislip, 2005, pp. 68-99). En el siglo anterior, Benito de Nursia, el más afamado de los legisladores occidentales, había establecido que "ante todo y por encima de todo lo demás, ha de cuidarse de los enfermos» (RBened. 36). Retornando al caso hispano, las reglas elaboradas en la segunda mitad del siglo VII en el no- roeste peninsular, sea la de Fructuoso o la Regula Communis, no se apartan mucho de lo que hasta aquí hemos visto; a pesar de que proceden de un ambiente aparentemente más aislado y más alejado de las tradiciones clásicas. La Regula communis establece para el cuidado de los monjes unas disposiciones que apenas se diferencian de las vistas en Isidoro:

Los enfermos, de cualquier enfermedad que adolezcan, han de residir en una sola casa y han de estar encomendados a un solo individuo apto para ello; y deben ser atendidos con tales servicios, que no echen de menos el afecto de los parientes ni las comodidades de la ciudad, sino que el despensero y el prepósito proveerán lo que fuere necesario. Por su parte los enfermos deben estar advertidos con todo cuidado de que no salga de su boca ni la más pequeña ni ligera palabra de murmurador [...]; el monje que les sirve en modo alguno llegue a molestarles. Por lo que si [...] saliere de su boca el escándalo de la murmuración [...] deba acusarlos el encargado de este ministerio (RCom. 7).

Dado el peculiar carácter de los monasterios regidos por esta regla, donde profesan familias enteras y hay una residencia de hombres y otra de mujeres, la misma prevé que haya una enfermería masculina y otra femenina. Aunque no está expresamente anotado, se desprende que sea así cuando manda «que todos los monjes enfermos yazgan en monasterio de varones [...] que ni la madre, ni hermana, ni esposa, ni hija, ni pariente, ni extraña, ni criada, ni cualquiera otra clase de mujer sirvan a los varones durante su enfermedad» (RCom.17), señalando a continuación la reciprocidad de su mandato en todo lo referido a la relación de varones y mujeres durante el periodo de enfermedad. En el caso de Fructuoso no se hace alusión a un lugar específico de enfermería, pero la afirmación de que "los enfermos deben ser tratados con toda compasión y lástima, y sus dolencias aliviadas con los servicios convenientes» (RFruct.9), probablemente lleva implícita la existencia de una dependencia específica. De hecho, el monasterio fructuosiano sí prevé una zona concreta para los ancianos, equiparados en su caso a los enfermos:

Se les coloca aparte en una celda más espaciosa, con servidores escogidos por el abad, se les da de comer a la hora sexta y el que no quiera comer no se le obliga. Se seleccionan servidores entre aquellos que por naturaleza no sean débiles, para que atiendan a los demás ancianos, como también a los enfermos (aegrotis), y a los enfermizos (languentibus) a los que cuidarán con piadosos y benévolos servicios (RFruct.23). 
Esta referencia a los ancianos tiene un interés específico. Por un lado, ha introducido una gradación de salud entre enfermo y enfermizo, que marca la diferencia entre un estado circunstancial y una naturaleza permanentemente débil. El capítulo insinúa, por otra parte, el papel que los monasterios desempeñan como lugar privilegiado de atención a un sector poblacional especialmente desprotegido. Podemos imaginar que el texto de Fructuoso está aludiendo exclusivamente a los monjes que llegan a la ancianidad, sin embargo, es posible que fuesen, en sí mismos, centros de acogida de aquellos miembros de las comunidades del entorno que, llegados a una edad avanzada, resultasen un lastre para sus familias. En el caso de la Regula communis no parece haber ninguna duda al respecto: "Suelen venir al monasterio muchos novicios ancianos, y reconocemos que muchos de ellos prometen el pacto más por su forzosa debilidad que por miras religiosas» (RCom. 8).

El largo capítulo establece las condiciones en las cuales deben de ser admitidos, se trata de una colección de normas adecuadas a su edad, esencialmente la voluntad de renunciar al mundo pasado y de corregir los hábitos de conducta que una vida mundana ha marcado. Colaborando, según las fuerzas que cada uno conserve, en trabajos ligeros, excluyéndoles «del servicio de la panadería y de la cocina; y libres del trabajo duro del campo». En todo caso, solo en circunstancias extremas serán expulsados de la comunidad; el capítulo contempla catorce amonestaciones previas antes de ser sometidos al juicio de la asamblea, solo si llegados a este punto no muestran voluntad de corregirse deberán abandonar el monasterio.

De nuevo, en estas reglas tardías, el tratamiento de los enfermos parece reducirse a la dieta. Isidoro considera que la carne debe tomarse solo cuando se sale para un largo viaje o para los monjes enfermos, en este caso se recomienda la carne de ave (RFruct. 3). En el resto de las ocasiones los monjes se alimentarán "solo de verduras y legumbres, y raras veces de peces de río o de mar», a lo que se añade el vino, un sextario (poco más de medio litro) a repartir entre cuatro monjes, aunque no puro. En los días festivos se permite alguna excepción. Y de igual modo en la Regula communis, donde carne, sidra o vino parecen reservarse a los enfermos, los ancianos o aquellos que evidencian una manifiesta debilidad, y siempre con el beneplácito de los superiores del monasterio (RCom. 19). En otro momento, la regla advierte que los pastores no deben descuidar las ovejas, porque "de ellas se sustentan los enfermos, de ellas se nutren los niños, de ellas se sostienen los ancianos, [...] de ellas se atienden a los huéspedes y viajeros» (RCom. 9).

En ninguno de los casos se alude directamente a otros tratamientos. La figura del medicus es ajena a los procedimientos curativos de los monasterios. En dos ocasiones en que la profesión es mencionada, esta aparece en el contexto de dos símiles médicos empleados por la Regula communis. Referencias que no dejan de ser curiosas, en un caso se alude a que el médico corta la carne en mayor o menor profundidad según el estado de putrefacción de la herida: Quia et medicus tantum profundius uulnera abscisit quantum pútridas carnes uidet (RCom. 8); en el otro recurre igualmente a un ejemplo médico-quirúrgico: «porque también el médico (medicus) suspende la incisión (incisione) del enfermo (aegrotum) cuando advierte que puede ser curado con medicinas (medicamina)» (RCom. 19). Sin embargo, en ninguna de las reglas aparece la figura de un médico, todo lo más un ministro infirmorum (RCom. 17; RFruct. 9). Las habilidades quirúrgicas parecen excepcionales y quedarían reducidas a aquellos profesionales elitistas mencionados en la Lex Visigothorum, ocasionalmente recordados en la epigrafía (Vives, 1942, p. 91, no 288), quizás a los servicios incluidos entre las urbium delicias mencionadas en otro momento (RCom.7); donde podían contarse los médicos de la misma iglesia (VSPE 4.2.21), o los ocasionales centros de atención, como el xenodochium que Masona habría fundado en la ciudad de Mérida (VSPE 5.3.13-26; Stasolla, 1998; Risse, 1999, p. 79-83; Mateos Cruz, 2003). Ahora bien, la falta de testimonios no excluye que, al menos en el caso de los monasterios urbanos o periurbanos, los servicios de un médico profesional pudiesen ser solicitados en caso necesario.

Pero, como norma general, incluso los medicamina parecen fuera de las posibilidades de la enfermería monástica. Más allá de las excepciones dietéticas, de los alimentos delicados, de la ingesta de carne y de vino o sidra, de la liberalidad en los horarios de comida, del descargo de actividades pesadas o de cualquier tipo de trabajo, del mejor acomodo a la hora del sueño en beneficio de incrementar las posibilidades de descanso, la única vez que se alude a la ingestión de algún principio activo curativo, se trata de los remedios que los parientes femeninos de un monje pueden llevar a este bajo supervisión de la abadesa, responsable de las pro- 
fesas en el contexto de los 'monasterios familiares' que la regla ampara. El nombre adjudicado a la 'medicina' proporcionada es sorbitiuncula (RCom. 17), probablemente en el sentido de un brebaje, una pócima o bebedizo, no muy alejada en su composición de remedios populares anteriores a la introducción del medicamento (Riddle, 1990), como lo habría entendido el mismo Isidoro: Antiquior autem Medicina herbis tantum et sucis erat (Etym. 4.9.4). Quien, por otro lado, en uno de sus poemas, asume que los pobres no pueden recurrir a las caras hierbas, bálsamos y especias de Oriente y deben conformarse con pratorum germinis herbas, útiles para muchas curas (Versvs 19). Otra evidencia de que existía una medicina para ricos y otra para pobres. En el caso de cansancio extremo, los viajeros que llegan a la hospedería del monasterio reciben friegas de aceite (RFruct.9), la forma más elemental de aplicar un bálsamo relajante (Etym. 4.12.6).

Un lugar común en buena parte de la historiografía sobre los monasterios antiguos es discernir en qué medida estos se convirtieron en hospitales, lo que parece evidenciarse en las grandes fundaciones orientales (Miller, 1997, pp. 118-140; Horden, 2005; Crislip, 2005, pp.100-142; Mayer, 2015). Es probable que, en las grandes ciudades occidentales de peregrinación, en torno a centros cultuales de importancia excepcional, algunos monasterios supliesen a los xenodochia, o conviviesen con ellos (Sternberg, 1991, pp. 277-279; Dey, 2004). Ahora bien, el nivel médico que los monasterios visigodos parecen evidenciar no se asocia con un centro curativo, sus cuidados parecen esencialmente paliativos, asociados a una 'reparación' del cuerpo débil, o fatigado, y quizás algunas curas esenciales por medio de emplastes o hierbas. No hay descripción de patologías específicas, cuyo conocimiento debemos esencialmente a las evidencias osteológicas (Menéndez Bueyes, 2013, pp. 32-50 y 67-115), salvo quizás las alteraciones de conducta y los súbitos cambios de humor asociados con la senectud: continuo in iracundian prosiliunt, et per diuturnum tempus tristitiae morbo stimulantur [...] Et cum frequenter et inmoderate in tale uitio dilabuntur, tristia eum deserit, solita consuetudine in fabulis et risu frena laxantur (RCom. 8). Lo que es seguro es que los monasterios se convirtieron en posadas para viajeros y peregrinos, sólo en este contexto de ejercicio de la caridad cristiana puede entenderse que los monasterios visigodos actuasen como hospitales, como lugares de atención a enfermos ajenos a la comunidad (Linage Conde, 1970, p. 204).
Isidoro, cuando describe las tareas que corresponden a cada cual, especifica que los monjes elaborarán su propio pan, pero que a los legos les corresponde hacerlo para huéspedes y enfermos (Rlsid. 21). Debemos entender en la contraposición que se trata de enfermos no monjes. La hospedería es un lugar importante del monasterio, a ella se dedica mucha atención en las reglas, en ella se emplean, en lo que es considerado un trabajo especialmente duro, los que pretenden ingresar en el monasterio, durante tres meses en el caso de los monasterios isidorianos (RIsid. 4), un año completo en aquellos para los cuales fue escrita la regla de Fructuoso (RFruct. 20). Incluso, esa atención parece claramente especificada por este último, cuando en el capítulo de hospitibus suscipiendis precisa que «los enfermos deben ser tratados con compasión y lástima, y sus dolencias aliviadas con los servicios convenientes» (RFruct. 9). Ahora bien, no se trataría de una institucionalización de la atención médica, forma parte del ejercicio de las máximas evangélicas, aquí aplicadas a los peregrinos y a los pobres transeúntes. Un texto anónimo de época visigoda, el De monachis perfectis, anota que una de las tareas de los monjes urbanos es visitar a los enfermos y a los encarcelados: infirmos et in carceribus positos visitant (Díaz y Díaz, 1958, p. 83), pero no parece que sea más que la aplicación de una obra de misericordia (Linage Conde, 1970, p. 205). La posibilidad de que el monasterio de Agali, en los suburbios de Toledo, hubiese tenido una vinculación médica, incluso un centro especializado de formación (Riche, 1962, p. 344), no parece tener otro apoyo que el de su advocación a los santos Cosme y Damián, que las tradiciones cristianas asociaban a los grandes médicos de la antigüedad: Cosmas Damianus Hippocrates Gal<i>enus (Versvs 16).

En todo caso, y más allá de esta perspectiva marcada por la ausencia de testimonios, es posible que algunos monasterios guardasen recetarios. Sabemos que el recurso a drogas, o fármacos, remedios basados esencialmente en compuestos de hierbas, ocasionalmente elementos biológicos animales, es un procedimiento universal que recibió un gran impulso en época helenística. El mismo Galeno, que nos informa de esta tradición (Totelin, 2009), parece haber sido un entusiasta defensor de esta farmacología que se basaba, en el mejor de los casos, en el ensayo/ error, cuando no directamente en referentes de una magia simpática (Keyser, 1997). Isidoro recoge esta amalgama de principios científicos y mágicos al tratar De remediis et medicaminibus (Etym. 4.9), donde des- 
cribe las cualidades curativas de algunas hierbas (dinamidia), a las que se añaden otras referencias en el libro dedicado a la agricultura (Etym. 17. 7-9), pero en ningún caso podemos hablar de remedios explicitados con composición y proporciones, o modo de aplicación. Por lo tanto, si estos recetarios pasaron a una forma escrita, su sistematización no resulta evidente para esta época, como, sin embargo, sabemos que proliferaron en la península ibérica a finales de la edad media (Cifuentes i Comamala, 2016). El único testimonio positivo lo proporciona Alejandro de Tralles, un médico bizantino enciclopedista del siglo VI que viajó por el Mediterráneo recopilando remedios médicos, llegado a Hispania recogió una sofisticada receta contra la epilepsia (Scarborough, 1984; Vallejo Girvés, 2002); por desgracia, no sabemos de dónde la tomó. Finalmente, tan tarde como en el siglo X, el visir de Abd-al Rahman III subió a uno de los monasterios de la montaña de Córdoba, sucesores mozárabes de la tradición visigoda, para buscar un remedio con el que atajar una otitis del Califa. Le recomendaron aplicarle en el oído sangre caliente de un palomo recién sacrificado y el remedio parece haber resultado eficaz (Vernet, 1968). Esta noticia podría considerarse una evidencia, tardía, de que los monasterios visigodos habían transmitido, junto a otros conocimientos, algunos de esos hipotéticos recetarios.

\section{EL MONJE ENFERMO. ENTRE EL CUIDADO DEL CUERPO Y LA SALVACIÓN DEL ALMA}

Para entender mejor el alcance de las soluciones médicas, y de la misma definición de enfermedad, que aparecen implícitas en los textos monásticos visigodos, probablemente todo lo analizado hasta aquí resulte insuficiente. Si contrastamos el conocimiento médico a disposición de los contemporáneos, sea simplemente a partir de las Etimologías de Isidoro, o de los parcos textos legislativos, con las soluciones aportadas por las reglas analizadas, da la sensación de que hay una traslación muy pobre. En sus escritos enciclopédicos Isidoro parece tener claro que la enfermedad tiene un origen físico, que la medicina es una actividad legítima, que dentro de ella él ha asumido que la dieta es la primera forma de curación y que conscientemente, al aplicar sus conocimientos al desarrollo práctico de la regla monástica, ha renunciado a las otras dos.

No obstante, vimos que Isidoro definía la medicina dietética como una forma de vida, y esto puede in- terpretarse como algo más que una terapia. De hecho, cuando nuestro autor abandona su faceta de enciclopedista y adopta una perspectiva teológica, no tiene inconveniente en clasificar las enfermedades del hombre desde otra escala de valores:

Por tres motivos sobrevienen las enfermedades corporales; esto es, por el pecado, por la tentación y por la pasión de la intemperancia; pero solo a esta última puede aplicársele un remedio humano; en cuanto a las otras, solo la piedad de la divina misericordia (Sentent. 3.3.4).

La intemperantia es la falta de templanza, el abuso de los sentidos, la incapacidad de someter las pasiones. La vinculación entre el vicio, siempre asociado al pecado, y la enfermedad va a ser un lugar común en el pensamiento cristiano medieval, aunque no es un elemento novedoso (Ferngren y Amundsen, 1985). Si nosotros analizamos con detalle la percepción teológica de la enfermedad presentada por Isidoro, enseguida descubrimos que las ideas racionales de las Etimologías han pasado a un segundo plano.

Cuando Dios ve que algunos no quieren corregirse por propio impulso, les excita con el aguijón de la adversidad. Asimismo, previendo que otros pueden cometer muchos pecados, quebranta su salud con la enfermedad corporal para que no pequen, a fin de que les sea más provechoso quedar abatidos por la debilidad para la salud de su alma que permanecer con buena salud para su condenación (Sentent. 3.3.2).

Es más, una salud vigorosa es una invitación a los deseos ilícitos, una ocasión para el pecado, y, de manera especial, para la pasión de la lujuria (Sentent. 3.3.5). Estas ideas subyacen en todas las reglas analizadas, de manera clara en la del propio Isidoro:

No ha de alimentarse el cuerpo hasta la hartura, para que no se ahogue el espíritu, pues con la hartura del vientre se excita pronto la lujuria de la carne. $Y$ el que reprime la pasión de la gula, domina indudablemente los movimientos de lascivia (R/sid. 9).

Aunque, como hemos comprobado en otros casos, los argumentos de Isidoro parecen ir apenas un paso por detrás de los esgrimidos por su hermano Leandro, quien en sus recomendaciones a la común hermana Florentina ha construido una auténtica antropología de la negación del cuerpo:

Cuando el cuerpo disfruta de salud, hay que imponerle ayunos, y aquellos a los que por ley del pecado se les subleva la carne rebelde deben domeñarla con ayuno frecuente. La carne insumisa ha de doblegarse a base de ayunos y debe ser refrenada hasta que obedezca como 
una esclava a los dictados de la razón y a las órdenes del espíritu (RLeand. 18).

Un poco más adelante insiste sobre el particular al advertir contra los inconvenientes del consumo de carne:

La que tiene suficiente vigor debe abstenerse de tomarla, pues es duro en extremo nutrir al enemigo contra el que se ha de luchar y alimentar la propia carne para que se torne rebelde [...] Alimentarse de carnes es incentivo de vicios; y no solo de carnes, sino el exceso de cualquier otro alimento; porque no es la calidad del manjar lo que se reprueba como vicio, sino la cantidad. Todo lo que se toma en exceso grava el espíritu; y el estómago debilitado por alimento abundante en demasía embota los sentimientos del alma. La virgen simplemente ha de estar sana, no robusta; su rostro debe parecer pálido, no sonrosado (RLeand. 24).

Resulta indudable que la salud del cuerpo ha pasado a un segundo plano. El régimen alimenticio, que en la definición médica era una cura para restaurar el equilibrio del cuerpo, es ahora un mecanismo para buscar la salud del alma. El discurso médico y el discurso teológico parecen ya definitivamente convergentes. Leandro asocia directamente el consumo de carne con la voluptuosidad, pero no es solo una cuestión de calidad, sino también de cantidades, la saciedad puede encender el impulso sexual y eso debe evitarse a toda costa (Linage Conde, 1972; Castillo Maldonado, 2002, pp. 44-50). La antropología cristiana sobre el cuerpo humano había vivido en un difícil equilibrio entre una percepción positiva, aquella que justificaba el uso de la medicina y la curación, y otra absolutamente negativa que la rechazaba (Amundsen, 1996), al considerar que el cuerpo era una cárcel para el alma, un recipiente pecaminoso que la arrastraba hacia la perdición (Cacitti, 1976; Brown, 1991, pp. $83-102$, 160-165 y 428-447; Sfameni Gasparro, 1998). El cuerpo debe ser controlado, dominado, sometido, modelado hasta convertirlo en un objeto capaz de reflejar la pureza de Dios que lo había creo a su imagen y semejanza (Miller, 1998, pp. 281-300; Clarke, 2005). Reprimir la pasión de la gula y mortificarse con la abstinencia son las armas de las que el hombre dispone para dominar las pasiones (Rlsid. 3). $Y$ esto, que en origen habría sido una opción voluntaria, intelectual, del asceta cristiano o de sus equivalentes paganos, pasa a convertirse en una imposición colectiva, que alcanza en la disciplina monástica su mayor exaltación.

El abad Eutropio, que a finales del siglo VI sería obispo de Valencia, había anotado que el exceso de comida y de bebida atraía la lujuria y el deseo carnal (Díaz y Díaz, 1958, pp. 29-30). Fructuoso tiene claro que el régimen alimenticio está en directa relación con la actividad sexual; al tratar de los desenfrenados (lasciuis) dice:

El que se jacta de su desenfreno debe quedar privado con frecuencia de alimento y mortificado con ayunos de dos o tres días [...] Si después de sufrir estos castigos reiteradas veces no se corrigiere, se le corregirá con más energía por medio de azotes y se le encerrará en larga reclusión; se le alimentará con escasísima ración de pan y agua hasta que prometa que se apartará del vicio (RFruct. 14).

La renuncia al consumo de carne se presenta como el elemento central en la dieta que prefigura el camino hacia la virtud. La limitación en el consumo de agua, además de la comida, también está en Isidoro (Rlsid. 9), quien en otro lugar afirmará «que para la castidad es conveniente también abstenerse de agua» (Sentent. 2.43.8; Di Marco, 2018); mientras que carne, sidra o vino se les prohíbe en la Regula communis, a quienes hubiesen cometido graves pecados en el siglo, y la razón es la misma, evitar el fomento de la lascivia (RCom. 19). Fructuoso se ve obligado a advertir que la prohibición de comer carne no se debe a que se considere a los animales que se consumen como criaturas indignas de Dios, sino porque su renuncia es útil para los monjes; castigando el quebrantamiento de la prohibición con seis meses de reclusión (RFruct. 3). Misma pena, agravada con un régimen reducido a solo un poco pan de cebada al atardecer, está prevista para aquellos monjes aficionados a los niños (RFruct. 15; Díaz, 2018). Resulta evidente al legislador que, en estos casos, la dieta calórica mínima no ejercía suficiente fuerza apaciguadora, por lo que esta se reduce a aportes exiguos que garantizasen el aniquilamiento de su mismo ímpetu o voluntad (Riera Melis, 1999). La dieta ya no es solo el camino para lograr el equilibrio del cuerpo (Temkin, 1991, pp. 149-180), es esencialmente una cura para el alma. Isidoro, inmerso en una antropología marcada por el pesimismo, considera que quien se siente culpable cuando es arrebatado por las pasiones del cuerpo, siempre se halla en pena (Castillo Maldonado, 2004, pp. 38-39). Como recuerda el hispalense en los Synonyma, el hombre será incapaz de vencer las tentaciones si no tiene al ayuno por aliado, por cuanto la gula engendra la lujuria que debe ser vencida por la sed y el hambre (Synon. 158; Fontaine, 1965; Zaragoza Rubira, 1966-1967; Picci Donati, 2007, pp. 29-43). El monje debe comer poco, lo esencial para 
un equilibrio estable acorde con sus obligaciones cotidianas, "que no se agote por completo y que no goce demasiada libertad»(Sentent. 2.44.13); debe remitirse a una gama de alimentos perfectamente establecidos, aquellos considerados más adecuados para el apaciguamiento del deseo, un régimen hidratante y secante, la xerofagia, que el mismo Isidoro explica es la «abstinencia de consumir alimentos húmedos» (Etym. 6.19.70; Rousselle, 1989, p. 34; Grimm, 2004). En definitiva, el monje debe ayunar siempre que pueda, porque:

Los ayunos constituyen armas eficaces frente a las tentaciones diabólicas, ya que con la abstinencia se vencen pronto [...], pues los espíritus inmundos se lanzan con mayor violencia allí donde ven más abundancia de manjares y bebidas. // Los santos, mientras pasan la vida en este mundo, mantienen su cuerpo sediento por el deseo del rocío celeste [...] Porque entonces la carne está sedienta de Dios cuando por el ayuno guarda abstinencia y languidece. La abstinencia vigoriza y mata: vigoriza el espíritu y mata el cuerpo (Sentent. 2.44.3-4).

\section{A MANERA DE EPÍLOGO}

La imagen de Isidoro como transmisor de la medicina clásica ha sido objeto de una indudable atención. Hoy en día es posible que nadie pueda defender su originalidad, es apenas un intérprete de Galeno, de los principios hipocráticos, a los que ha llegado a través de lecturas indirectas, muchas veces de resúmenes o simplificaciones tardías. De la lectura de las
Etimologías resulta imposible sacar conclusiones válidas sobre las prácticas médicas de la época. De hecho, al presentar el cuerpo de sus saberes eruditos, no pretendíamos una propuesta original, sino, solamente, que sirviese como contraste a la práctica médica cotidiana del periodo visigodo que ha sido, comparativamente, poco estudiada.

En este sentido, la especial atención prestada a la enfermería monástica creemos que constituye el elemento más innovador de este estudio. Por un lado, el mismo Isidoro, en cuanto legislador monástico, evidencia hasta qué punto era profundo el abismo que separaba su acumulación enciclopédica de su comprensión de la medicina en cuanto práctica curativa. De su cuerpo científico apenas ha pasado al texto de su Regla monástica una preocupación por la dieta, donde, además, adelantando lo que será la doctrina imperante durante toda la Edad Media y buena parte de la modernidad, no evidencia tanto una preocupación por la salud del cuerpo como por la del alma. Por otra parte, la riqueza de las fuentes monásticas visigodas, complementada con la legislación y algunas fuentes colaterales y anecdóticas, permite una aproximación a las prácticas de la medicina cotidiana en la Hispania del siglo VII. Ahora bien, la pobreza aparente de la práctica médica, parece contrastar con la fama curativa de algunos monasterios del periodo mozárabe, lo que quizás implique que, donde las fuentes no alcanzan, la medicina pudo ser una preocupación del estudio monástico, al menos de algunos monasterios concretos.

\section{NOTAS}

1 Las fuentes en el texto han sido citadas de acuerdo a las siguientes abreviaturas, ediciones y traducciones:

Etym. = Isidoro de Sevilla, Etymologiae (CPL 1186). Ed. y trad. Oroz Reta; Marcos Casquero, 2004.

$L V=$ Leges Visigothorum. Ed. Zeumer, 1902.

RBened. = Benito de Nursia, Regula (CPL 1852). Ed. y trad. Colombás y Aranguren, 1979.

RCom. $=$ Regula communis (CPL 1870). Ed. y trad. Campos y Roca, 1971, pp. 172-208.

RFruct. = Fructuoso de Braga, Regula Complutensis (CPL 1869). Ed. y trad. Campos y Roca, 1971, pp. 137-162.

RLeand. = Leandro de Sevilla, De institutione uirginum et de contemptu mundi libellus (CPL 1183). Ed. y trad. Velázquez Arenas, 1979, pp. 97-174.

Sentent. $=$ Isidoro de Sevilla, Sententiae (CPL 1212). Ed. Cazier, 1998; trad. Campos y Roca, 1971, pp. 226-525.

Synon. = Isidoro de Sevilla, Synonyma (CPL 1203). Ed. Elfassi, 2009.

Versvs $=$ Isidoro de Sevilla, Versus (CPL 1212). Ed. Sánchez Martín, 2000.

VSPE = Vitas Sanctorum Patrum Emeretensium (CPL 2069). Ed. Maya Sánchez, 1992.

Rlsid. $=$ Isidoro de Sevilla, Regula Monachorum (CPL 1868). Ed. y trad. Campos y Roca, 1971, pp. 90-125. 


\section{BIBLIOGRAFÍA}

Alvarado Planas, Javier (1997), El problema del germanismo en el derecho español. Siglos V-XI, Madrid, Marcial Pons.

Amundsen, Darrel W. (1982), "Medicine and Faith in Early Christianity", Bulletin of History of Medicine 56, pp. 326-350.

Amundsen, Darrel W. (1996), "Tatianu's "Rejection" of Medicine in the Second Century". En: Medicine, Society, and Faith in the Ancient and Medieval Worlds, Baltimore-London, The Johns Hopkins University Press, pp. 158-174.

Andorlini, Isabella; Marcone, Arnaldo (2004), Medicina, medico e società nel mondo antico, Firenze, Le Monnier.

Bejarano Osorio, Ana María (2015), La medicina en la Colonia Augusta Emerita, Mérida, Instituto de Arqueología de Mérida-CSIC.

Borgongino, Bruno U. (2011), "A conduta dos monges enfermos na Regula Isidori (615-619)". En: Anais do XXVI Simposio Nacional de Historia - ANPUH - Sao Paulo, pp. 1-10, [en línea], disponible en: [http://www.snh2011.anpuh.org/resources/anais/14/1300473616_ARQUIVO_Bruno_Anpuh2011.pdf [consultado el 07/10/2018].

Borobia Melendo, Enrique Luis (1988), Instrumental médicoquirúrgico en la Hispania romana, Madrid, Editorial Numancia.

Brown, Peter (1991), The Body and Society. Men, Women and Sexual Renunciation in Early Christianity, London-Boston, Faber and Faber.

Cacitti, Remo (1976), “L'etica sessuale nella canonistica del cristianesimo primitivo. Aspetti dell'istituzionalizzazione ecclesiastica nel III secolo". En: Cantalamessa, Raniero (ed.), Etica sessuale e matrimonio nel cristianesimo delle origini, Milano, Università Cattolica del Sacro Cuore, pp. 69-157.

Campos, Julio; Roca, Ismael (1971), Santos padres españoles. II. San Leandro, San Isidoro, San Fructuoso. Reglas monásticas de la España visigoda. Los tres libros de las Sentencias, Madrid, La Editorial Católica.

Castillo Maldonado, Pedro (2002), "Gastrimargia y abstinentia gulosa en la normativa monástica hispanovisigoda (I): Leandro de Sevilla", Florentia lliberritana 13, pp. 33-52.

Castillo Maldonado, Pedro (2004), "Gastrimargia y abstinentia gulosa en la normativa monástica hispanovisigoda (II): Isidoro de Sevilla", Florentia lliberritana 15, pp. 29-55.

Cardelle de Hartmann, Carmen (2014), “Uso y recepción de las Etymologiae de Isidoro". En: Codoñer, Carmen; Alberto, Paulo (eds.), Wisigothica. After Manuel C. Díaz y Díaz, Firenze, Sismel-Edizioni del Galluzzo, pp. 477-501.

Cazier, Pierre (1998), Isidorus Hispalensis, Sententiae [CC SL 111], Turnhout, Brepols.

Cifuentes i Comamala, Lluis (2016), "El receptari mèdic baixmedieval i renaixentista: un gènere vernacle". En: Badia, Lola; Cifuentes, Lluís; Martí, Sadurní; Pujol, Josep (eds.), Els manuscrits, el saber i les lletres a la Corona d'Aragó, 12501500, Rubí, Abadía de Montserrat, pp. 103-160.
Clarke, Gillian (2005), "The Health of the Spiritual Athlete". En: King, Hellene (ed.), Health in Antiquity, London-New York, Routledge, pp. 216-229.

Codoñer Merino, Carmen (2005a), "Isidorus Hispalensis ep. Etymologiae". En: Chiesa, Paolo; Castaldi, Lucia (eds.), La trasmissione dei testi latini del Medioevo, vol. 2, Firenze, Sismel-Edizioni del Galluzzo, pp. 274-299.

Codoñer Merino, Carmen (2005b), "La medicina en algunos escritos de Isidoro de Sevilla". En: Ferraces Rodríguez, Arsenio (ed.), Isidorus medicus. Isidoro de Sevilla y los textos de medicina, A Coruña, Universidad de A Coruña, pp. 65-84.

Colombás, García M.; Aranguren, Iñaki (1979), La Regla de San Benito, Madrid, La Editorial Católica.

Crislip, Andrew T. (2005), From Monastery to Hospital. Christian Monasticism and the Transformation of Health Care in Late Antiquity, Ann Arbor, The University of Michigan Press.

Curado, Blas (2004), La medicina en Mérida según la vida de los Padres Emeritenses [Cuadernos Emeritenses 25], Mérida, Museo Nacional de Arte Romano.

Dey, Henrik W. (2004), “Diaconiae, xenodochia, hospitalia and monasteries: 'social security' and the meaning of monasticism in early medieval Rome", Early Medieval Europe 16/4, pp. 398-422.

Díaz, Pablo C. (1998), "El testamento de Vicente: propietarios y dependientes en la Hispania del s. VI". En: Hidalgo, María J.; Pérez, Dionisio; Gervás, Manuel J.R. (eds.), "Romanización" y "reconquista" en la Península Ibérica: nuevas perspectivas, Salamanca, Universidad de Salamanca, pp. 257-270.

Díaz, Pablo C. (2007), "Espacio real / espacio imaginado en los monasterios isidorianos". En: López Quiroga, Jorge; Martínez Tejera, Artemio M.; Morín de Pablos, Jorge (eds.), Monasteria et Territoria. Elites, edilicia y territorio en el Mediterráneo medieval (siglos $V-X I$ ), [BAR International Series S1720], Oxford, Hadrian Books, pp. 77-90.

Díaz, Pablo C. (2017), “Las fundaciones monásticas en la península ibérica (siglos VI-VIII)". En: Monachesimo d'Oriente e d'Occidente nell'Alto Medioevo (LXIV Settimane di studio della Fondazione Centro Italiano di Studi sull'Alto Medioevo, Spoleto, 31 marzo-6 aprile 2016), Spoleto, CISSAM, pp. 463-497.

Díaz, Pablo C. (2018), "Discipline and punishment in $7^{\text {th }}$ century Visigothic monasticism: The contrast between Isidore's and Fructuosus' rules". En: Alciati, Roberto (ed.), Norm and Exercise. Christian asceticism between late antiquity and early medieval ages, Stuttgat, Franz Steiner, pp. 107-123

Díaz y Díaz, Manuel C. (1958), Anecdota wisigothica l. Estudios y ediciones de textos literarios menores de época visigoda, Salamanca, Universidad de Salamanca.

Díaz y Díaz, Manuel C. (2009), "Introducción general”. En: Oroz Reta, José; Marcos Casquero, Manuel (eds.), Isidoro de Se- 
villa. Etimologías. Edición bilingüe, Madrid, La Editorial Católica, pp. 1-257.

Di Marco, Michele (2018), “Dum ad dormiendum uadunt. Note sul lessico isidoriano relativo alle tentazioni notturne dei monaci (Isid. reg. monach. 13)", Paideia 73, III/III, pp. 1953-1967.

Elfassi, J. (2009), Isidorus Hispalensis: Synonima [CC SL 11B], Turnhout, Brepols.

Fernández Alonso, Justo (1955), La cura pastoral en la España romanovisigoda, Roma, Iglesia Nacional Española.

Ferngren, Gary B.; Amundsen, Darrel (1985), "Virtue and Health/Medicine in Pre-Christian Antiquity". En: Shelp, Earl E. (ed.), Virtue and Medicine (Philosophy and Medicine, 17), Dordrecht, Springer, pp. 3-22.

Ferngren, Gary B. (2009), Medicine and Health Care in Early Christianity, Baltimore, The John Hopkins University Press.

Ferraces Rodríguez, Arsenio (1994), "El pseudo-Dioscórides De herbis femininis, los Dynamidia e Isidoro de Sevilla, Etym. 17,7-11". En: Vázquez Buján, Manuel E. (ed.), Tradición e innovación de la medicina latina de la Antigüedad y de la Alta Edad Media, Santiago de Compostela, Universidad de Santiago de Compostela, pp. 183-203.

Ferraces Rodríguez, Arsenio (2005a), "Isidoro de Sevilla y los textos de medicina". En: Ferraces Rodríguez, Arsenio (ed.), Isidorus medicus. Isidoro de Sevilla y los textos de medicina, A Coruña, Universidad de A Coruña, pp. 11-37.

Ferraces Rodríguez, Arsenio (2005b), "Aspectos léxicos del Libro IV de las Etimologías de Isidoro de Sevilla en manuscritos médicos altomedievales". En: Ferraces Rodríguez, Arsenio (ed.), Isidorus medicus. Isidoro de Sevilla y los textos de medicina, A Coruña, Universidad de A Coruña, pp. 95-127.

Fidora, Alexander (2000), "La recepción de San Isidoro de Sevilla por Domingo Gundisalvo (ca. 1110-1181): Astronomía, Astrología y Medicina en la Edad Media", Estudios eclesiásticos 75, pp. 663-677.

Fischer, Klaus-Dietrich (2000), "The Isagoge of Pseudo-Soranus. An Analysis of the Contents of a Medieval Introduction to the Art of Medicine", Medizine Historisches Journal 35, pp. 3-30.

Fischer, Klaus-Dietrich (2005), "Neuer oder vernachlässigte Quelle der Etymologien Isidor von Seville (Buch 4 und 11)". En: Ferraces Rodríguez, Arsenio (ed.), Isidorus medicus. Isidoro de Sevilla y los textos de medicina, A Coruña, Universidad de A Coruña, pp. 129-174.

Flemming, Hugh (2010), Pos-Hippocratic Medicine: The Problem and the Solution. How the Christian Ethic Has Influenced Health Care, Taunton, Kuyper Foundation.

Fontaine, Jacques (1959), Isidore de Seville et la culture classique de l'Espagne wisigothique, 2 vols, Paris, Études Augustiniennes.

Fontaine, Jacques (1965), “Isidore de Séville auteur 'ascétique': les énigmes des 'synonyma'", Studi Medievali, 3a serie, 6, pp. 163-195.
Fontaine, Jacques (1988), "Isidore de Sèville et la mutation de l'encyclopedisme antique», Cahiers d'histoire mondiale 9, pp. 519-538.

Fortacín, Javier (1983), "La donación del diácono Vicente al monasterio de Asán y su posterior testamento como obispo de Huesca en el siglo VI. Precisiones críticas para la fijación del texto", Cuadernos de Historia Jerónimo Zurita 47-48, pp. 7-70.

Freire Camaniel, José (2002), "El Liber regularum y el Codex regularum del monacato prebenedictino". En: Domínguez García, Manuela (ed.), Sub Luce Florentis Calami. Homenaje a Manuel C. Díaz y Díaz, Santiago de Compostela, Universidad de Santiago de Compostela, pp. 350-358.

García-Ballester, Luis (1994), “Medicina universitaria y no universitaria en la Castilla de los siglos XIII y XIV". En: González Iglesias, Juan Antonio; Codoñer Merino, Carmen (coords.), Antonio de Nebrija, Edad Media y Renacimiento, Salamanca, Universidad de Salamanca, pp. 335-345.

García-Ballester, Luis (2001), La búsqueda de la salud: sanadores y enfermos en la España medieval, Barcelona, Península.

García-Ballester, Luis (2013), "The Construction of a New Form of Learning and Practicing Medicine in Medieval Latin Europe", Science in Context 8, pp. 75-102.

García-Ballester, Luis (2013), "On the origin of the 'sex nonnatural things' in Galen". En: Kollesch, Judit; Nickel, Diethard (eds.), Galen und hellenistische Erbe, Stuttgartt, Franz Steiner, pp. 105-115.

García Pérez, Antonio (2001), "De Morbis qui in superficie corporis videtur (San Isidoro de Sevilla, año 621): Primer texto de dermatología en Europa", Anales de la Real Academia Nacional de Medicina 118, pp. 219-227.

Granjel, Luis S. (1981), La medicina española antigua y medieval, Salamanca, Universidad de Salamanca.

Grant, Mark (2000), Galen on Food and Diet, London-New York, Routledge.

Grimm, Veronika E. (2004), From feasting to fasting, the evolution of a sin. Attitudes to food in late antiquity, LondonNew York, Routledge.

Grmek, Mirko D. (1998), Western Medical Thought from Antiquity to the Middle Ages, Cambridge (Mass.)-London, Harvard University Press.

Hankinson, Robert H. (2008), "Philosophy of nature”. En: Hankinson, Robert H. (ed.), The Cambridge Companion to Galen, Cambridge, Cambridge University Press, pp. 210-241.

Heyne, Thomas (2011), "Tertullian and Medicine", Studia Patristica 50, pp. 131-174.

Horden, Peregrine (2005), "The Earliest Hospitals in Byzantium, Western Europe, and Islam", Journal of Interdisciplinary History 35/3, pp. 361-389.

Jackson, Ralph (1990), "Roman doctors and their instruments: Recent research into ancient practice", Journal of Roman Archaeology 3, pp. 5-27. 
Jouanna, Jacques (2012), "Wine and Medicine in Ancient Greece". En: Jouanna, Jacques, Greek Medicine from Hippocrates to Galen. Selected Papers, Leiden, Brill, pp. 173-193.

Kaster, Robert A. (1988), Guardians of Language. The Grammarian and Society in Late Antiquity, Berkeley-Los AngelesLondon, University of California Press.

Keyser, Paul T. (1997), "Science and Magic in Galen's Recipes (Sympathy and Efficacy)". En: Debru, Armelle (ed.), Galen on Pharmacology: Philosophy, History and Medicine (Proceedings of the Vth International Galen Colloquium, Lille, 1618 March 1995), Leiden, Brill, pp. 175-198.

Kibre, Pearl (1945), "Hippocrates Writings in the Middle Ages", Bulletin of the History of Medicine 18, pp. 371-412.

Kulikowski, Michael (2007), "Plague in Spanish Late Antiquity". En: Little, Lester K. (ed.), Plague and the End of Antiquity. The Pandemic of 541-750, Cambridge-New York, Cambridge University Press, pp, 150-170.

Laín Entralgo, Pedro (1961), Enfermedad y pecado, Barcelona, Toray.

Linage Conde, Antonio (1970), "La enfermedad en la organización monástica visigoda”, Asclepio 22, pp. 203-217.

Linage Conde, Antonio (1972), "Algunos aspectos biológicos de la Regula Leandri", Cuadernos de Historia de la Medicina Española 11, pp.309-324.

López Piñero, José M.; Ferrandiz Araujo, Carlos (2008), Medicina en las Etimologías de San Isidoro, Murcia, Real Academia de Medicina y Cirugía.

Maire, Brigitte (2005), "Isidore de Séville, lecteur de Gargilius Martialis". En: Ferraces Rodríguez, Arsenio (ed.), Isidorus medicus. Isidoro de Sevilla y los textos de medicina, A Coruña, Universidad de A Coruña, pp. 179-213.

Martín, José C. (2002), La Renotatio Librorum Domini Isidoro de Braulio de Zaragoza (+651). Introducción, edición crítica y traducción, Logroño, Fundación San Millán de la Cogolla.

Martínez Gázquez, José (2005), “Isidoro de Sevilla y la medicina en los enciclopedistas hispanos: D. Gundisalvo y Juan Gil de Zamora". En: Ferraces Rodríguez, Arsenio (ed.), Isidorus medicus. Isidoro de Sevilla y los textos de medicina, A Coruña, Universidad de A Coruña, pp. 215-225.

Mateos Cruz, Pedro (2003), "Xenodochium, Mérida”. En: Mateos Cruz, Pedro; Caballero Zoreda, Luis (eds.), Repertorio de Arquitectura Cristiana en Extremadura. Época Tardoantigua y Altomedieval, Mérida, Instituto de Arqueologia de Mérida-CSIC, pp. 89-94.

Maya Sánchez, Antonio (1992), The Vitas Sanctorum Patrum Emeretensium [CC SL 116], Turnhout, Brepols.

Mayer, Wendy (2015), "Medicine in Transition: Christian Adaptation in the Later Fourth Century East". En: Greatex, Geoffrey; Elton, Hugh (eds.), Shifting Genres in Late Antiquity, Ashgate, Farnham, pp. 11-26.

Menéndez Bueyes, Luis R. (2013), Medicina, enfermedad y muerte en la España tardoantigua. Un acercamiento histórico a las patologías de las poblaciones de la época tardo- romana e hispanovisigoda (siglos IV-VIII), Salamanca, Universidad de Salamanca.

Miller, Patricia C. (1998), "Dreaming the Body: An Aesthetic of Asceticism". En: Wimbush, Vincent L.; Valantasis, Richard (eds.), Ascetism, Oxford, Oxford University Press, pp. 281-300.

Miller, Timothy S. 1997 (1985), The Birth of the Hospital in the Byzantine Empire, Baltimore-London, The Johns Hopkins University Press.

Montero Cartelle, Enrique (2003), "La literatura técnica latina de época tardía: aspectos lingüísticos y literarios”. En: Álvarez, Dulce E.; Domínguez García, Manuela; Amado Rodríguez, María T. (eds.), El final del mundo antiguo como preludio de la Europa moderna, Alcalá de Henares-Santiago de Compostela, Universidad de Alcalá de Henares, pp. 259-280.

Mundó Marcet, Anscari M. (1957), "Il monachesimo nella Penisola Iberica fino al sec. VII". En: II monachesimo nell'alto medioevo e la formazione della civiltà occidentale (IV Settimane di Studio del Centro italiano di Studi sull'alto medioevo, Spoleto 8-14 aprile 1956), Spoleto, CISSAM, pp. 73-117.

Noy, Jo N. (2006), "Historians and Epidemics: Simple Questions, Complex Answers". En: Little, Lester K. (ed.), Plague and the End of Antiquity. The Pandemic of 541-750, Cambridge-New York, Cambridge University Press, pp. 33-56.

Nutton, Vivian (2004), Ancient Medicine, London-New York, Routledge.

Nutton, Vivian (2008), "The fortunes of Galen”. En: Hankinson, Robert H. (ed.), The Cambridge Companion to Galen, Cambridge, Cambridge University Press, pp. 351-390.

Oroz Reta, José; Marcos Casquero, Manuel (2004), Isidoro de Sevilla. Etimologías. Edición bilingüe, Madrid, La Editorial Católica.

Peset y Vidal, Juan B. (1962), “Memoria sobre medicina hispano-goda", Cuadernos de Historia de la Medicina Española 1, pp. 5-23.

Petit, Carlos (1982), “Lex Visigothorum 11.1: De medicis et egrotis", Cuadernos de Historia de España 67-68, pp. 5-32.

Petit, Carlos (1983), Fiadores y fianzas en el derecho romanovisigodo, Sevilla, Universidad de Sevilla.

Piazza, Emanuele (2007), "La lebbra tra malatia e peccato nell'Alto Medioevo", Annali della Facoltà di Scienze della Formazione. Università degli Studi di Catania 6, pp. 5-20.

Picci Donati, Francesca (2007), Dieta, salute, calendari. Del regime stagionale antico ai regimina mensium medievali: origine di un genere nella letteratura medica occidentale, spoleto, CISSAM.

Rather, Lelland J. (1968), "The six things non-natural: a note on the origins and fate of a doctrine and phrase", Clio Medica 3, pp. 337-347.

Rémy, Bernard; Faure, Patrice (2010), Les médecins dans l'Occident romain (Péninsule Ibérique, Bretagne, Gaules, Germanies), Paris-Bordeaux, De Boccard. 
Riche, Pierre (1962), Éducation et culture dans l'Occident barbare, $6^{\mathrm{e}}-8^{\mathrm{e}}$ siècles, Paris, Éditions du Seuil.

Riddle, John M. (1990), "High medicine and low medicine in the Roman Empire". En: Aufstieg und Niedergang der römischen Welt (ANRW) II. 37. 1. Wissenschaften (Medizin und Biologie), Berlin-New York, De Gruyter, pp. 101-120.

Riera Melis, Antonio (1999), "Las restricciones alimenticias como recurso expiatorio en algunas reglas monásticas de los siglos VI y VII", Aragón en la Edad Media 14-15 /2, pp. 1303-1316.

Risse, Guenter B. (1999), Mending Bodies, Saving Souls. A History of Hospitals, New York-Oxford, Oxford University Press.

Roca, María J. (2015), "La distinción entre patrimonio eclesiástico y privado de obispos y clérigos en la España visigoda", e-SLegal History Review 20, pp. 1-16.

Rosen, Ralph M. (2012), "Spaces of Sicknes in Greco-Roman Medicine". En: Baker, Patricia A.; Nijdam, Han; Van't Land, Karine (eds.), Medicine and Space. Body, Surroundings and Borders in Antiquity and the Middle Ages, Leiden-Boston, Brill, pp. 227-243.

Rosenberg, Charles E. (1992), Explaining epidemics and other studies in the history of medicine, Cambridge, Cambridge University Press.

Rousselle, Aline (1989), Porneia. Del dominio del cuerpo a la prohibición sensorial, Barcelona, Península.

Sánchez Martín, José M. (2000), Isidori Hispalensis Versus [CC SL 113A), Turnhout, Brepols.

Scarborough, John (1984), "Early Byzantine Pharmacology", Dumbarton Oaks Papers 38, pp. 213-232.

Sfameni Gasparro, Giulia (1998), “Asceticism and Anthropology: Enkrateia and 'Double Creation' in Early Christianity". En: Wimbush, Vincent, L.; Valantasis, Richard (eds.), Asceticism, Oxford, Oxford University Press, pp. 127-146.

Sharpe, William D. (1964), Isidore de Seville: The Medical Writings. An English Translation with an Introduction and Commentary [Transactions of The American Philosophical Society 54, 2], Philadelphia, The American Philosophical Society.

Sigerist, Henry E. (1943), Civilisation and Disease, Ithaca, Cornell University Press.

Stasolla, Francesca R. (1998), "A propósito delle strutture assistenziali ecclesiastiche: gli xenodochi", Archivio della Società Romana di Storia Patria 121, pp. 5-45.

Stathakopoulos, Dionysios Ch. (2004), Famine and Pestilence in the Late Roman and Early Byzantine Empire. A Systematic Survey of Subsistence Crises and Epidemics, Aldershot, Ashgate.

Stathakopoulos, Dionysios Ch. (2006), “Crime and Punishment. The Plague in the Byzantine Empire, 541-749". En: Little, Lester K. (ed.), Plague and the End of Antiquity. The Pandemic of 541-750, Cambridge-New York, Cambridge University Press, pp. 99-118.

Sternberg, Thomas (1991), Orientalium more secutus. Räume und Institutionen des Caritas des 5. Bis 7. Jahrhunderts in Gallien, Münster, Aschendorff.
Temkin, Owsei (1979), "Medical ethics and honoraria in late antiquity". En: Rosenberg, Charles E. (ed.), Healing and History. Essays for George Rosen, New York, Science Hist. Publ., pp. 6-26.

Temkin, Owsei (1991), Hippocrates in a World of Pagans and Christians, Baltimore-London, The John Hopkins University Press.

Totelin, Laurence M. V. (2009), “Galen's Use of Multiple Manuscript Copies in his Pharmacological Treatises". En: Doody, Aude; Taub, Liba (eds.), Authorial Choice, Authorial Voice: Greco-Roman Scientific and Medical Writing, Trier, Wissenschaftlicher, pp. 81-92.

Vallejo Girvés, Margarita (2002), "Alejandro de Tralles y un 'curioso' remedio hispano contra la epilepsia a mediados del siglo VI d. C.". En: Crespo, Santos; Alonso Ávila, Ángeles (eds.), Scripta Antiqva in Honorem A. Montenegro Duque et J. M. Blázquez Martínez. Magistris Optimis, Valladolid, Editores, pp. $815-826$

Van Der Eijk, Philip J. (2005), Medicine and Philosophy in Classical Antiquity. Doctors and Philosophers on Nature, Soul, Health and Disease, Cambridge, Cambridge University Press.

Vázquez Buján, Manuel E. (1991), "Notas sobre la pervivencia tardoantigua de Galeno". En: López Férez, Juan A. (ed.), Galeno. Obra, pensamiento e influencia, Madrid, UNED, pp. 223-233.

Vázquez Buján, Manuel E. (2005), “Isidoro de Sevilla y los libros de medicina. A propósito del antiguo comentario latino a los Aforismos hipocráticos". En: Ferraces Rodríguez, Arsenio (ed.), Isidorus medicus. Isidoro de Sevilla y los textos de medicina, A Coruña, Universidad de A Coruña, pp. 243-262.

Velázquez Arenas, Jaime (1979), Leandro de Sevilla. De la instrucción de las vírgenes y desprecio del mundo. Traducción estudio y notas, Madrid, Fundación Universitaria Española.

Vernet, Juan (1968), "Los médicos andaluces en el 'Libro de las generaciones de médicos' de Ibn Yulyul", Anuario de Estudios Medievales 5, pp. 444-462.

Vives, José (1942), Inscripciones cristianas de la España romana y visigoda, Barcelona, CSIC.

Vogt, Sabine (2008), "Drugs and Pharmacology". En: Hankinson, Robert H. (ed.), The Cambridge Companion to Galen, Cambridge, Cambridge University Press, pp. 304-322.

Zaragoza Rubira, Juan R. (1966-1967), "Enfermedad del alma y medicina del alma en la obra de San Isidoro", Asclepio 18-19, pp. 579-589.

Zaragoza Rubira, Juan R. (1968), "La medicina hispano-goda según las actas conciliares", Cuadernos de Historia de la Medicina Española 7, pp. 15-34.

Zeumer, Karl (1902), Leges Visigothorum [MGH Leges, I], Hannover, Hahn. 